\title{
Retomada de um legado intelectual Marialice Foracchi e a sociologia da juventude
}

Maria Helena Oliva Augusto

Menos do que uma etapa cronológica da vida, menos do que uma potencialidade rebelde e inconformada, a juventude sintetiza uma forma possivel de pronunciar-se diante do processo histórico e de constitui-lo. FORACCHI, 1965, p. 303

Nenhuma geração pode privar a juventude da possibilidade e do direito de levar a cabo suas próprias experiências. Por outro lado, nenhuma geração pôde fazer isso até agora. HeLleR, 1981 [1980]*, p. 203

Como o título deste artigo menciona, sua intenção é recuperar um legado, isto é, tornar presente a preciosa contribuição para o estudo da juventude corporificada na obra de Marialice Foracchi ${ }^{1}$. Abrange, num mesmo movimento, a aspiração de apresentá-la e ao seu trabalho àqueles que não a conheceram e a expectativa de reativar a memória, dos que foram seus contemporâneos, acerca do tratamento pioneiro - e ainda relevante - que deu ao tema ${ }^{2}$. Questôes que despertaram o seu interesse e às quais se dedicou como a situação, o papel e a polissemia da noção de juventude ${ }^{3}$, o conceito de geração e a coexistência de gerações, os processos de transição para a vida adulta, o estudante como categoria social e o significado dos movimentos juvenis no mundo contemporâneo, entre outros correlatos - receberam, por parte dessa estudiosa, um tratamento deveras apurado, que ainda pode servir de estímulo e diretriz para os(as) analistas contemporâneos(as).
*A data entre colchetes refere-se à edição original da obra. Elaéindicada na primeira vez que a obraécitada. Nas demais, indica-se somente a edição utilizada pelo autor (N.E.).

1. Marialice Foracchi (1929-1972) foi docente e pesquisadora da antiga cadeira de Sociologia I da Faculdade de Filosofia, Ciências e Letras - USP, dirigida por Florestan Fernandes, e do Departamento de Ciências Sociais da Faculdade de Filosofia, Letras e Ciências Humanas, que a sucedeu em virtude da reforma por que passou a universidade em 1969. 
2. Ao mesmo tempo, deseja realçar a importante percepção de que a retomada da reflexão sobre o tema, neste número, além da homenagem que lhe é prestada, representa também a reapropriação, formalmente expressa, de uma herança preciosa pelo atual Departamento de Sociologia, ao qual pertenceria não fosse sua morte prematura.

3. Para Marialice, "não sendo passível de delimitação etária, a juventude representa, histórica e socialmente, uma categoria social gerada pelas tensōes inerentes à crise do sistema. Sociologicamente, ela representa um modo de realização da pessoa, um projeto de criação institucional, uma alternativa nova de existência social" (1972, p. 160). No contexto desta discussão, também deve ser considerada a imprecisāo do conceito, o que acarretou a declaração de sua inexistência- " 'a juventude' não existe” - por um estudioso (cf. Lagrée, s/d) que se apóia em artigo de Bourdieu (1980). Assim, quando não estiver vinculado aos textos de Foracchi, o termo será utilizado como re-
De fato, a obra de Marialice deve ser vista como "clássica": na medida em que seus estudos permanecem centrais para a discussão atual desses temas e ainda hoje é possível aprender com seus textos, a autora e sua obra merecem um lugar privilegiado em relação a outros trabalhos e a outros estudiosos contemporâneos da juventude e dos temas que lhe são vinculados. Sua reflexão permanece viva e traz contribuições para o campo de conhecimento de que tratou, mesmo tendo passado quarenta anos da publicação do livro que a tornou mais conhecida ${ }^{4}$.

Algumas observações são, contudo, necessárias. O relativo esquecimento que tem atingido os seus trabalhos deve ser creditado, até certo ponto, ao refluxo sofrido pelo tema que foi objeto de sua tese de doutorado - a condição de estudante e sua atuação política -, especialmente após os anos de 1980. A partir de então, os processos de mudança que se manifestaram com mais força, no Brasil, fizeram emergir e deram mais realce a outros objetos de reflexão, a outros movimentos sociais, com protagonistas até então menos destacados (cf. Sader, 1988), minimizando a relevância dos movimentos estudantis e da sua possível contribuição para a transformação social.

Todavia, é necessário enfatizar que os achados e as reflexões da autora não se circunscreveram à discussão dessa categoria social; tampouco ficaram limitados à análise de suas possibilidades, como fonte de contestação da ordem social. Na medida em que se mantinha vinculada ao seu tempo e às questôes propostas por ele, Marialice pôde reconhecer e incorporar à sua reflexão a emergência de indagaçôes ainda hoje centrais para o debate sobre a condição juvenil e sobre a sociedade moderna. Desse modo, ainda que deva ser reconhecido o declínio do interesse pelo movimento estudantil, é necessário manter viva a consciência de sua importância, apreciar com respeito os assuntos que lhe são ligados e relembrar que, nas pesquisas sobre essa matéria, a autora abordou um amplo conjunto de outros tópicos e trouxe para o debate vários temas correlatos, sobre os quais sua visão permanece pertinente e pode ser utilizada ainda hoje. São esses achados o objeto preferencial e mais específico deste balanço.

A reflexão que se segue pretende, assim, recuperar alguns dos principais destaques propostos pela autora em seus trabalhos, relembrando pontos centrais tratados em seus textos ${ }^{5}$ e, o que se espera de modo especial, mostrando sua importância e enfatizando as contribuições que oferecem para o exame de questôes atuais relativas aos jovens e à juventude, temas que, já há algum tempo, vêm sendo retomados com alguma ênfase nas preocupaçōes das ciências sociais ${ }^{6}$. 
Como já mencionado, a construção da categoria social "estudante" e o tratamento dado ao movimento estudantil constituem os temas que, de início, tornaram Marialice conhecida, especialmente após a publicação, em 1965, do estudo em que focalizava o papel dos estudantes na transformação brasileira (cf. Foracchi, 1965). Nesse texto, ela ressalta ser "totalizadora, histórica e participante a perspectiva interpretativa que pretend[ia]" pôr em ação. Também destaca que a tarefa da abordagem sociológica é "caracterizar o conjunto de mecanismos e processos que presidem à constituição do estudante como categoria social" e examinar as "condiçôes sociais que balizam o seu comportamento", no presente, projetando as "modalidades possíveis de ampliação do seu horizonte de ação", no futuro (Foracchi, 1965, pp. 3-8).

A relação estabelecida entre as duas dimensões temporais que demarcavam a vida de estudante - presente e futuro -, evidenciando as perspectivas e as alternativas disponíveis para as trajetórias juvenis, já naquele momento constituía um ponto a ser realçado. A análise a que se propôs contribui, sem dúvida, para a avaliação desse mesmo elo no momento atual, como se pretende demonstrar.

As relações interpessoais e as manifestaçōes vinculadas à situação de classe, além da referência aos processos de transformação da sociedade inclusiva, foram os pontos destacados na análise do estudante como categoria social (cf. Foracchi, 1965, "Introdução"). De certo modo, articulando esses três níveis que permitiam equacionar de forma abrangente o processo de construção dessa categoria, a autora pôs em relevo a dinâmica educacional, na medida em que a educação é vista, com freqüência, como capaz de propiciar a ascensão social, tanto do indivíduo como do grupo. Também esse ponto será retomado a seguir.

Marialice considerava que as relações de classe representam objetivamente "os padrões de pensamento e de experiência inerentes ao estilo de convivência da sociedade moderna" (Foracchi, 1965, p. 66), e também avaliava como constitutivos do comportamento e da ação estudantis os vínculos entre o estudante universitário - estrato focalizado - e a classe média. Por esse motivo, a noção de classe aparece como forte suporte para a análise (cf. Idem, p. 11).

Da mesma forma, as situaçôes interpessoais constituem elemento importante para a configuração da categoria estudantil, uma vez que definem e regulamentam as relaçõos dinâmicas em que jovens e adultos estão envol- ferência ao período de vida que se estende até os 30 anos de idade, apenas para distingui-lo do estágio adulto e da velhice, que atualmente também possuem contornos imprecisos.

4. Sobre o significado de "clássico", ver a discussão desenvolvida por Alexan$\operatorname{der}(1991$ [1987]).

5. Os livros $O$ estudante e a transformação da sociedade brasileira, publicado há quarenta anos, e $A$ juventude na sociedade moderna, objeto de sua tese de livre-docência, receberão uma leitura mais detida; serão examinados também alguns artigos reunidos no livro A participação social dos excluidos, publicado postumamente (cf. Foracchi, 1965; 1972; 1982).

6. Como evidências dessa retomada, além do interesse de estudiosos mais experientes, atraídos pelo conhecimento da juventude atual, podem ser citados trabalhos de iniciação científica, dissertações de mestrado e teses de doutorado produzidos a partir dos anos de 1990, alguns já publicados. Reporto-me àqueles aos quais tive acesso, originariamente apresentados no 
Departamento de Sociologia - FFLCH, na Faculdade de Educação, no Instituto de Psicologia, da USP, e no Instituto de Filosofia e Ciências Humanas, da Unicamp. Ver Abramo (1994), Corrochano (2001), Jardim (2004), Oliveira (2001; 2005), Pimenta (1998; 2001; 2005), Silva (2003), Sousa (1999), Spagnol (2002), Valle (1999).

7. Nessa acepção, o estudante é visto como agente social da transitoriedade das camadas médias e porta-voz de sua ideologia de ascensão (cf. Foracchi, 1965, p. 119).

8. Para Foracchi, "o conceito sociológico de geração não se baseia exclusivamente na definição social da idade, mas encontra no conflito sua categoria constitutiva” (1972, p. 160). A dimensão do conflito aparece nas atitudes de oposição e de recusa do estilo predominante de existência social, redefine-se nos planos pessoal, institucional e societário, e é, por conseguinte, compartilhada por jovens e adultos.

9. A dependência significa um tipo de relação social no qual os laços de vidos. São duas as formas exploradas das relaçóes interpessoais. De um lado, a referência à família, grupo social específico no interior do qual se desenvolvem relações de manutenção. Estas formalizam a situação de classe no nível das relaçôes interpessoais, pois propiciam uma modalidade de ajustamento entre o jovem e o adulto que envolve o modo pelo qual ambos são socialmente categorizados (cf. Idem, p. 60). De outro lado, é incluído o contato entre geraçôes ${ }^{8}$, para cuja caracterização Marialice se apóia fortemente na perspectiva mannheimiana (cf. Mannheim, 1952, pp. 276322). As questôes referentes à família e ao contato entre geraçōes ainda hoje são pertinentes para a discussão do tema "juventude".

Nos textos examinados, a reflexão sobre a experiência familiar e os contatos em seu interior é utilizada para caracterizar a situação específica das camadas médias, mas talvez possa ser estendida a outros estratos da população sem sofrer distorções. A reciprocidade aparece como um traço distintivo desse tipo de vínculo, como aliás ocorre em qualquer relação social. As várias posições nela existentes representam papéis complementares que, por sua vez, ensejam formas específicas de ajustamento e de tolerância mútua.

Entre outras funções, os pais atuam como provedores; assim, quando existem recursos disponíveis, os jovens são sustentados por sua família enquanto se mantêm estudando. A dependência ${ }^{9}$ econômica não chega a preocupá-los, pois consideram esse encargo parte da obrigação familiar, sendo portanto "natural". A aparente gratuidade dessa manutenção, que afigura não exigir nenhum retorno por parte dos jovens, revela-se, entretanto, não tão desinteressada.

Fica claro que a obrigatoriedade de sustento por parte da família sem encargos correlatos é uma crença sem fundamento, já que é exigida uma contrapartida por parte do jovem estudante. Também é evidente que "os elementos permanentes de tensão ou de oposição que caracterizam as relaçôes entre jovens e adultos" (Foracchi, 1965, p. 21) ficam encobertos pelas idéias de despojamento e gratuidade, ainda que isso não seja obrigatoriamente notado pelos envolvidos. Os vínculos que essa situaçáo origina demonstram ser muito fortes: de fato, eles permitem o estabelecimento de um controle familiar, incessante e sem tréguas, que restringe as perspectivas sobre amplos domínios da vida juvenil e delimita as alternativas disponíveis, incluindo manifestações individuais de vontade (cf. Idem, cap. 1).

Sucede, todavia, que, se a atuação familiar é vista como investimento, que trará seus ganhos no futuro, havendo a expectativa de que as dificuldades presentes sejam recompensadas com as conquistas vindouras, isso 
não diminui a demanda por respostas adequadas dos jovens no momento em que a dependência é clara: esses laços são ampliados, atingindo diretamente a sua pessoa (cf. Idem, caps. 3 e 4$)^{10}$.

Há, portanto, um compromisso de retribuição que é amplo e permanente, e envolve o papel conferido ao jovem nos planos familiares de ascensão (ou de manutenção de posição) social. Assim, essa obrigação implica responsabilidade, tanto em relação ao seu próprio destino pessoal como em relação ao destino familiar. Seu compromisso é o de fazer efetivas as conquistas e de propiciar novos avanços. Assim, ainda que configurada no presente, a dívida pode ser deslocada para o futuro, na medida em que existe a expectativa de que sua realização profissional possibilite a manutenção ou a melhora da posição relativa da família em termos de estratificação social.

É ambíguo o sentido das relaçôes de dependência existentes entre os estudantes e suas famílias: de um lado, elas contêm potencialidades criadoras; de outro, envolvem limitações evidentes. Marialice relembra que "o modo de reagir ao vínculo é limitado pela própria instituição que o põe em prática” (Idem, p. 27). Entretanto, ainda que a subordinação dos jovens pareça total, ela não é completamente passiva e, em algumas situações, eles conseguem fazer sua vontade prevalecer. Desse modo, estão presentes tanto a submissão como a rebelião, parâmetros do seu agir que não são obrigatoriamente opostos (cf. Idem, pp. 23-27, 69).

Aí está também manifesto um paradoxo: como lembra Marialice, "somente os estudantes totalmente mantidos pelos pais e desligados de qualquer preocupação imediata com seu próprio sustento podem reconhecerse livres para empreender uma 'atuação de ensaio'” que lhes permita vôos novos. Se comparada à dos jovens não-estudantes, essa situação de manutenção constitui um privilégio. Entretanto, o compromisso familiar de mantê-lo como estudante provoca "a obrigação correspondente de [o jovem] sentir-se vinculado e de agir de acordo com as expectativas formadas" pela família a seu respeito. Assim, a busca de novos modos de agir e de viver, característica do comportamento juvenil, torna-se mais difícil, quando não é quase inteiramente contida (cf. Idem, cap. 1).

O jovem é um ser em formação, cujo destino depende de um jogo incerto de fatores. Tanto quanto possível, a família coordena esse jogo, incubando, no presente, condiçōes que só se configurarão no futuro. Por isso, suas expectativas, no que concerne ao jovem, se intercalam entre esses dois amplos momentos de realização pessoal, sem deixar de inculcar no imaturo uma filosofia prática de vida, cujo reciprocidade se transformam em compromissos de retribuição, situação social em que está presente um estilo de convivência peculiar ao grupo, explicitando vínculos que reproduzem as tensões atuantes no sistema inclusivo, variam socialmente e se refletem no comportamento individual dos participantes. Assim, esses laços não apenas representam as expressōes variáveis do comportamento humano, mas, com referência à sociedade de classes, denotam as condiçōes sociais objetivas de sua realização. Dessa forma, na mesma sociedade podem existir diferentes estilos de convivência e de dependência (cf. Foracchi, 1965, cap. 2).

10. A discussão do sentido assumido pela relação entre "presente" e "futuro" será feita mais adiante. 
11. Foracchi contrasta as relaçōes de dependências com as possibilidades de emancipação encontradas pelo estudante, desse modo distinguindo situaçôes de autonomia e de heteronomia. "A autonomia [é definida] como a responsabilidade de manutenção fundamentada na redefinição dos papéis sociais do indivíduo. Essa condição, segundo a autora, só é concretizada na situação de trabalho, quando o estudante se firma como unidade autônoma de manutenção. Esse é o momento em que o papel social do jovem é redefinido e ele se torna provedor, seja do próprio sustento, seja do sustento da família" (Pimenta, 2001, p. 33).

12. A autora menciona ainda duas outras categorias de jovens que estudam e trabalham: aqueles para os quais "o trabalho se torna mais absorvente que o curso, fazendo com que o jovem abandone a perspectiva do estudante para pensar como homem de negócios", a experiência de trabalho propiciando a emancipação; e aqueles que atuam na política estudantil, que lhes aparece como tarefa decisiva, imperativo fundamental é: ser alguém. Percebe-se, assim, que as expectativas de retribuição, mesmo quando colocadas nesses termos, não são simplesmente deslocadas para o futuro. Apresentam, pelo contrário, a singularidade de redefinirse nesses dois planos temporais, fazendo com que, progressivamente, um se resolva no outro (Idem, p. 38).

É diferente a situação do estudante que trabalha ${ }^{11}$ : além de não depender da colaboração financeira da família para continuar estudando, muitas vezes ele é quem a ajuda. Como a família não pode sustentá-lo, para poder estudar o trabalho remunerado deixa de ser uma escolha e torna-se uma imposição. Com freqüência, a necessidade obriga o estudante a trabalhos insatisfatórios, que não têm sentido algum para ele além da remuneração que proporcionam, e não alteram significativamente os laços de dependência que mantém com a família; como é mencionado, "o trabalho, tal como aqui transparece, não se reveste de qualquer sentido claro de emancipação" (Idem, p. 48). A alternância das atividades torna sua vida fragmentada: trabalho e estudo preenchem tempos sociais distintos.

A situação do trabalhador que estuda é ainda mais expressiva das dificuldades envolvidas, pois, nesse caso, sua sobrevivência e a da família dependem da remuneração que recebe: "o trabalho mantém os vínculos entre o estudante e a família" (Idem, p. 49) mediante um compromisso informal, mas tácito. Esse compromisso afasta-o das possibilidades de dedicar-se à preparação para a carreira que escolheu - o curso, de fato, tem para ele importância acessória - e de ensaiar vôos próprios que lhe possibilitem entrar em contato com alternativas, políticas ou culturais, mais amplas. $\mathrm{O}$ vínculo impeditivo que o aprisiona é de caráter distinto, mas mais explícito: é a situação global que o produz ${ }^{12}$.

Para fechar o círculo das condições necessárias para a reconstrução interpretativa da categoria "estudante", um terceiro elemento é apresentado, relativo aos fatores que possibilitam o processo de transformação do sistema inclusivo e que se manifestam no nível prático da atuação estudantil-juvenil (cf. Idem, p. 11). Para Marialice, isso significa que "os fatores que definem as condiçốes de ajustamento do jovem ao adulto não se esgotam na esfera das relações interpessoais, mas são produzidos pela dinâmica da constituição do sistema global". Sob a forma de relação de manutenção, a situação de classe torna propícia uma modalidade de ajustamento entre jovens e adultos, que envolve o modo pelo qual ambos são socialmente categorizados. Como é ele o responsável pelo processo de socialização das geraçôes mais 
novas, "as pressões modeladoras do adulto induzem o jovem a formar-se de acordo com os padrões e com a problemática incorporada pelo grupo com o qual o adulto se identifica" (Idem, pp. 60-61) - assim, o padrão de dependência presente é ao mesmo tempo intersubjetivo e social.

É interessante comparar as situações observadas por Foracchi (1965, 1982) e aquelas encontradas em estudo sobre a transição para a vida adulta entre estudantes universitários de São Paulo (cf. Pimenta, 2001), mostrando as diferenças e as convergências que apresentam. Enquanto a primeira se concentrou nos estudantes vinculados à USP (cf. Foracchi, 1965, p. 9), no segundo caso o âmbito foi ampliado para abarcar (e comparar) alunos dessa universidade pública e de duas outras universidades particulares, a Unip e a Unicsul (cf. Pimenta, 2001, p. 59). Para fazer essa comparação, é necessário ressaltar que o acesso ao ensino superior é bastante distinto nos dois momentos, muito mais restrito em 1960; identificar as razões para a escolha das universidades particulares no estudo de $2001^{13}$; e mencionar que o estudo de Foracchi não focalizou estudantes de cursos específicos ${ }^{14}$, enquanto na segunda pesquisa a amostra foi constituída por estudantes de carreiras muito disputadas, Direito, Publicidade e Turismo ${ }^{15}$.

Alguns resultados aproximam-se bastante: da mesma forma que na pesquisa anterior (cf. Foracchi, 1982, pp. 64-82), a de 2001 (cf. Pimenta, 2001, pp. 67-113) constata que, apesar do aumento relativo de estudantes oriundos de estratos socioeconômicos menos privilegiados, a maioria dos que estudam na USP provém de camadas sociais superiores, no sentido de pertencerem a estatutos socioculturais e socioeconômicos mais elevados, em contraste com a variação mais acentuada encontrada nas universidades privadas. Por outro lado, em 2001, na USP, uma porcentagem significativa dos estudantes são filhos de pais com grau superior de escolaridade (na pesquisa de Foracchi, havia poucos nessas condições) ${ }^{16}$; em contraste,

[...] na Unicsul foi encontrada a maior parte dos estudantes oriundos de famílias de camadas sociais menos privilegiadas, em que a diferença entre o estatuto sociocultural e socioeconômico em relação às outras universidades é maior, e se observa um esforço maior por parte dos filhos de conquistarem um grau de instrução mais alto do que o alcançado pelos pais, assim como para alcançar ocupações profissionais de nível superior (Pimenta, 2001, p. 89).

Com relação aos primeiros, convergente com análise de Foracchi da década de 1960, está presente "uma estratégia familiar de manutenção do estatu- sem, no entanto, transformar trabalho e curso em atividades secundárias (cf. Foracchi, 1965, pp. 49-53). Elas, entretanto, não serão exploradas aqui.

13. "Devido ao grande número e variedade de universidades particulares na capital, foram selecionadas duas: a Unip (Universidade Paulista), atualmente considerada a maior universidade privada da América Latina, e a Unicsul (Universidade Cruzeiro do Sul) [...]. A escolha da Unicsul justifica-se pelo fato de essa universidade, localizada em um bairro tradicionalmente operário e [...] [com] uma população predominantemente de baixa renda, estar voltada para um público estudantil de perfil bastante diferenciado do público das outras universidades particulares" (Pimenta, 2001, pp. 59-60).

14. "A amostra utilizada correspondia a 5\% da população estudantil da Universidade de São Paulo em 1960, tal como se distribuía pelas diferentes faculdades que integram esse organismo universitário" (Foracchi, 1965, p. 9). 
15. "Para a definição dessas carreiras, foi examinado o registro da procura por cursos vestibulares da Fuvest durante dez anos (1990-2000) e identificadas: a) quais eram as carreiras tradicionalmente mais procuradas-as que mantiveram os maiores números de inscriçôes com pequena variação durante o período; b) quais eram as carreiras emergentes-as que apresentaram aumento do número de inscrições no período; e c) quais eram as carreiras que apresentaram uma concorrência alta e constante no período, em função da relação candidato vaga. A partir desses critérios, foram definidas: 1) carreiras tradicionais (foi escolhido o curso de Direito); 2) carreiras que emergiram na década de 1990-2000 (foi escolhido o curso de Publicidade); e 3 ) carreiras 'da moda', ou que se tornaram emergentes nos três anos anteriores à pesquisa (foi escolhido o curso de Turismo)" (Pimenta, 2001, pp. 48-60).

16. É importante lembrar que, apesar de a base socioeconômica dos estudantes que têm ingressado na USP estar sendo ampliada, diminuindo a concentração exis- to sociocultural já alcançado pela família" (Idem, p. 77); o interessante é que, a partir da pesquisa mais recente, é possível supor que, entre os últimos - e também entre aqueles que possuem uma situação econômica privilegiada, mas um nível de escolaridade mais baixo, ainda que exista uma diferença de significado nesse processo -, exista "uma estratégia familiar de ascensão social, em termos de capital escolar. Para uma família de condição social menos privilegiada, o investimento em educação superior faz parte de uma estratégia de ascensão social, em busca de opções mais rentáveis de atividade econômica" (Idem, p. 77).

Entretanto, na medida em que os estudantes provenientes de camadas sociais menos privilegiadas tendem a se formar em escolas públicas no ensino básico e a freqüentar a universidade particular, e, por sua vez, os estudantes provenientes de camadas sociais mais favorecidas tendem, em sua maioria, a se formar em escolas particulares no ensino básico e freqüentar a universidade pública, fica claro que as condições de disputa são mais difíceis e acirradas para os primeiros. Essa observação permite ratificar aquela feita pela pesquisa dos anos de 1960, sobre a importância atribuída à educação como fator de mobilidade social, mas também confirma a constatação de que existe certa ilusão na relação estabelecida entre ambas. Ou seja:

[...] A formação de nível superior [...] é, sobretudo, fator de consolidação da trajetória social já percorrida. [...] isso significa que a formação universitária representa menos uma oportunidade original de ascensão na escala social do que um prêmio que sanciona e legaliza a conquista de novas posições. [...] A educação universitária apenas ratifica uma trajetória social já realizada e para firmar-se como instrumento de realização pessoal e como recurso de afirmação pessoal não prescinde - pelo contrário, exige - de condições socioeconômicas estáveis e consolidadas (Foracchi, 1965, pp. 300-301).

Também é interessante apresentar a situação dos estudantes que trabalham, na pesquisa mais recente. Aqueles oriundos de famílias com capital escolar inferior começam a trabalhar mais cedo, aumentando a idade conforme o crescimento da renda mensal familiar. Os alunos da Unicsul apresentam a menor média de idade de início da vida ativa, os alunos da USP apresentam a maior, e os da Unip situam-se numa posição intermediária em relação às outras duas universidades. Quando a renda mensal é inferior a mil reais, o trabalho do jovem aparece como importante complemento da 
renda familiar. Nas demais faixas de renda, a motivação mais importante é ganhar dinheiro para o próprio consumo. Nesse caso, o trabalho proporciona a remuneração necessária para os gastos pessoais, aparecendo como uma alternativa para aqueles que não têm condições de receber uma mesada dos pais e também como possibilidade de maior autonomia, uma vez que esse dinheiro é administrado pelo próprio jovem. Nas faixas de renda mais altas, entretanto, a vontade de trabalhar aparece em uma porcentagem significativa, o que exprime uma visão do trabalho como uma experiência positiva e desejável (cf. Pimenta, 2001, pp. 100-105).

$\mathrm{Na}$ amostra dos estudantes da USP de 2001, predominam os pertencentes às camadas sociais mais favorecidas, oriundos de famílias com capital escolar superior, com renda mensal alta, cujos pais ocupam posiçóes profissionais mais credenciadas. Esses estudantes encontram maior autonomia na busca por uma ocupação profissional realizadora, na medida em que sua contribuição não é exigida para a obtenção da renda familiar. Portanto, têm mais tempo para dedicar aos estudos e à carreira universitária e podem optar pela situação de não-trabalho enquanto procuram alternativas de inserção no mercado que estejam de acordo com suas aspirações e expectativas. Em contraste, na amostra da Unicsul predominam aqueles oriundos de famílias cujo capital escolar é inferior e médio-inferior, com rendas mensais mais baixas, cujos pais ocupam posições profissionais menos credenciadas. Entre essas famílias, o jovem é estimulado a começar a trabalhar mais cedo, para complementar a renda mensal familiar e ajudar nas despesas da casa (cf. Idem, p. 107). Nesse caso, sua dedicação aos estudos é bem menor e não é surpreendente que sua vida estudantil se alongue ou seja interrompida, nem tampouco que o curso universitário falhe em lhe proporcionar a melhora profissional e social almejada ${ }^{17}$.

Duas categorias distintas emergem desse mapeamento - de um lado, o jovem; de outro, o estudante -, influenciando-se de forma recíproca e levantando uma questão de difícil resposta: "como ser estudante, categoria social independente, se não é possível deixar de ser, ao mesmo tempo, jovem dependente, submisso e comprometido?” (Foracchi, 1965, p. 28). Em outro momento, essa duplicidade é, entretanto, circunstanciada: ser estudante é um acidente na condição de jovem (cf. Foracchi, 1972, p. 110) e essa é a condição preferencialmente atingida pela crise social mais ampla (cf. Idem, p. 160). tente anteriormente, a pesquisa de 2001 focalizou estudantes das carreiras mais disputadas e nas quais a seleção é mais restritiva, o que, sem dúvida, concorre para o afunilamento das possibilidades de acesso.

17. Para constatar as dificuldades de acesso ao estudo universitário por jovens trabalhadores das camadas menos privilegiadas, cf. Oliveira (2001) e Silva (2003). 
Juventude, tempo e estilo de vida

18. Cf. nota 3 .

19. De fato, a percepção da existência de diferentes experiências juvenis e, assim, de várias juventudes é, hoje, um dado aceito e incorporado pelos estudiosos do tema. Vários dos artigos presentes neste número reiteram essa constatação.
A juventude ${ }^{18}$ é caracterizada a partir de um registro tríplice: o reconhecimento de que se trata de uma fase da vida, a constatação de sua existência como força social renovadora e a percepção de que vai muito além de uma etapa cronológica, para constituir um estilo próprio de existência e de realização do destino pessoal (cf. Foracchi, 1965, pp. 302-304).

Como etapa que antecede a maturidade, fase dramática da revelação do eu, essencial para a formação da pessoa, a juventude corresponderia a um momento definitivo de descoberta da vida e da história. A mobilização dos recursos e das potencialidades que possui depende diretamente das alternativas abertas aos jovens por sua inserção social, pelas posições que ocupam, pelos caminhos oferecidos para sua trajetória.

As trajetórias possíveis são estabelecidas socialmente. "Cada sociedade constitui o jovem à sua imagem" (Idem, p. 302), ou, utilizando outra formulação, impõe-lhe um modo de ser, que jamais poderia surgir a partir dele próprio cria-o (fabrica-o) como indivíduo social (cf. Castoriadis, 1982, p. 343).

A mesma sociedade pode produzir tipos de jovens bastante diversos, pois, originados de diferentes extraçôes sociais, inserindo-se em posições distintas e apropriando-se de hábitos e valores específicos de acordo com essa inserção, as "maneiras de ser" que lhes são impostas - ou que têm possibilidade de constituir - não são as mesmas para todos. Na distribuição diferencial que forçosamente ocorre, uns são mais privilegiados do que outros. Desse modo, fica claro que a juventude não é una, e que a diferenciação social e a diversidade econômica têm peso importante na configuração das distintas "maneiras de ser" impostas aos jovens ${ }^{19}$.

A juventude também é identificada como força dinamizadora da vida social, atuante em sua transformação, para o que se une a outras forças operantes na sociedade. De um lado, sua busca por uma sociedade mais justa leva-a a emergir como porta-voz dos desfavorecidos, revelando as formas de opressão existentes; de outro, sua flexibilidade permite-lhe experimentar novas alternativas e adaptar-se com relativa facilidade a modos de conduta e padrões de vida anteriormente desconhecidos (cf. Foracchi, 1965).

Entretanto, as mesmas características que fazem o jovem ser percebido como forjador do futuro podem aparecer com cores negativas; há sempre "outro lado", outra maneira de avaliar, a partir da qual suas qualidades são julgadas de forma ambivalente: o jovem é sério, mas imaturo; é audacioso, mas inexperiente; impulsivo, mas indeciso. Isso faz com que suas manifes- 
tações com freqüência sejam vistas somente como manifestações de espíritos rebeldes, avessos à ordem e propícios a promover distúrbios e atitudes inconseqüentes (cf. Foracchi, 1965).

Finalmente, para a autora, a juventude sintetizaria uma forma possível de pronunciar-se diante do processo histórico e de constituí-lo, configurando desse modo um estilo próprio de existência e de realização do destino pessoal. Citando Bettelheim (1962), lembra que a condição de jovem não se distingue das demais a não ser por sua capacidade singular de, ao longo da existência humana, recriar insatisfações vitais nunca definitivamente aplacadas. Trata-se, assim, de expressão da virtude que mantém vivas as capacidades de resistência, de disputa e de renovação (cf. Foracchi, 1965, pp. 303-304).

Adulto e jovem surgem como categorias socialmente distintas, vinculadas por um elo de continuidade e por interesses comuns. O que o primeiro torna efetivo como realização, o segundo significa como virtualidade. Configuram, portanto, papéis opostos, complementares e articulados: a passagem de uma condição social à outra é assinalada por um processo tenso (cf. Idem, pp. 56, 303).

É possível contrastar estilos de vida peculiares aos jovens e aqueles da maturidade, vivenciados pelos adultos. Enquanto as características juvenis referem-se principalmente a essa capacidade de vivenciar e dar origem ao novo, a condição social de adulto caracteriza-se pela independência econômica e emocional, e pela legitimação da atividade sexual, manifesta pelo casamento e pelo direito de estabelecer família. Em momentos diferentes da vida, dependendo de como reagimos ao que acontece, somos jovens inconformados ou adultos acomodados.

Quando discute o convívio entre geraçooes, Marialice lembra que a relação estabelecida entre os adultos e os jovens se caracteriza por um antagonismo constante e árduo, cuja modificação, sendo difícil, não é entretanto impossível. Nos termos em que propõe a discussão, o adulto aparece como portador da experiência à qual se contrapõe a inexperiência do jovem. Assim, o primeiro é aquele(a) que sabe o que deve ser feito e como deve sê-lo, enquanto o segundo aparece como aquele(a) que desconhece os percursos da vida e necessita de orientação. Desse modo, o adulto pode impor e o jovem deve submeter-se. Quando comparadas as duas posições, a condição de superioridade do primeiro fica inequívoca.

A autora menciona a necessidade de esse relacionamento ser subvertido, cada um dos termos sendo transformado em seu contrário: a inexpe- 
20. "A geração é definida como uma unidade e uma totalidade unificante, que resulta de um contexto idêntico de socialização, durante os primeiros anos de existência, quando as crianças e os adolescentes recebem a marca de sua época” (Lagrée, s/d). Diferente da nota 7 , em que é enfatizada a dimensão relacional dessa noção, geração está pensada aqui em relação àqueles que estão incluídos na mesma "unidade geracional, ou seja, são formad[os] por uma socialização similar, [e] também [constituem] uma comunidade de destino" (Idem). riência, antes um elemento de inferiorização dos jovens, pode ser transformada em fator de superioridade, na medida em que for levada em conta a capacidade inovadora, traço distintivo da juventude e fundamental num mundo em constante transformação. Cada situação nova deve ser vivida com novos recursos e a atitude prevalecente sempre necessita envolver uma recriação. Em outras palavras, a aparente superioridade adulta é relativa: afinal, a experiência que não possibilita a improvisação e o escape deliberado diante da rotina, que não supre com recursos originais a ausência de habilidade e conhecimento prévios, é de fato falsamente superior e pode ser vista como frustrada (e frustrante), além de inútil, num mundo que tem a mudança como elemento constitutivo (cf. Idem, pp. 24-26).

Num outro ângulo, é importante marcar que a distância entre geraçôes é sintoma de uma situação menos manifesta e que envolve um fato fundamental que lhe está subjacente: a contestação dos jovens às "certezas" da experiência dos mais velhos é reveladora da rejeição à própria condição adulta (cf. Foracchi, 1972, p. 16). Tal percepção propõe elementos importantes para discutir a relação intergeracional nos dias de hoje, que manifestam, décadas depois, um processo que já estava em curso naqueles anos.

Assim, num contexto diverso daquele em que Marialice sustentou a idéia de a juventude forjar um estilo próprio de existência, seu registro pode ser utilizado de outra forma, para pensar o momento contemporâneo. $\mathrm{Na}$ sociedade atual, em que a longevidade é mais freqüente, possibilitando a coexistência de várias gerações ${ }^{20}$, "o envelhecimento postergado transform[ou] o jovem, de promessa de futuro que era, em modelo cultural do presente" (Peralva, 1997, p. 230) Desse modo,

[...] a imagem da juventude [passou a] representa[r] o ideal de todas as idades. As pessoas desejariam permanecer jovens e conservar os atributos da juventude: a beleza do corpo, a vivacidade do espírito, a liberdade de escolha na ocupação do tempo, a capacidade de renovar-se constantemente [...] Em virtude disso, a idade adulta perdeu seu poder de sedução e não mais constitui a norma a atingir (Gauthier, 2000, p. 24).

"Ser jovem [passou a ser] um imperativo categórico para cada geração" (Finkielkraut, 1995, p. 130). Em virtude disso, a ansiedade em relação a "como permanecer jovem" se estende para muito além das idades conside- 
radas juvenis, tendo se tornado um objetivo aspirado por quase todos e cuja busca é incessante.

De qualquer modo, atualmente os mais jovens parecem desinteressados de incorporar à sua vida o trajeto percorrido e o legado das gerações anteriores. Ao mesmo tempo, os mecanismos sociais capazes de vincular a experiência pessoal dos que agora são jovens à que sustentava a conduta $\mathrm{e}$ as maneiras de ver o mundo das gerações que vieram antes já não podem ser facilmente ativados. Afinal, com as alterações significativas que ocorreram nos padrões de sociabilidade e nas formas de ser, essa experiência não tem validade para aqueles que estão no início de sua vida. Pode-se perceber, então, que o tempo decorrido é realmente passado, não faz mais sentido para a vida atual.

"Ser adulto", além de ter deixado de ser objetivo prioritário aspirado pelos mais jovens, nem sempre é valorizado positivamente. Na verdade, hoje, há certa recusa generalizada ao "crescer" e ao "amadurecer", que adquiriram a conotação de "envelhecer" (cf. Ahmadi, 2001, p. 192). Pode-se supor então que não só privilegiar o presente (viver o agora $^{21}$ ) tornou-se característica comum a todas as faixas etárias, como também buscar a juventude extrapola os estratos juvenis, já que (quase) todos querem ser, manter-se ou parecer jovens. Ao mesmo tempo, a juventude é considerada condição indispensável para que ocorra uma verdadeira experiência, o que promove clara inversão na maneira como a questão era proposta anteriormente. A experiência parece ter deixado de significar conhecimento ancorado na sabedoria do saber fazer, acervo de uma vida que pode ser transmitido, para resumir-se à vivência sem lastros do momento (cf. Benjamim, 1985a, 1985b).

Entretanto, como lembra Singly, tudo depende do significado atribuído à formulação "ser adulto": se fizer referência à aptidão para assumir responsabilidades, é identificado por pessoas mais jovens e mais velhas como característica sua; porém, se denotar "um ser acabado que não tem mais nada a descobrir no mundo e, sobretudo, nele próprio" (Singly, 2000, p. 10), é igualmente rechaçado por ambas as categorias.

Do mesmo modo como estava alterada a avaliação relativa ao "ser adulto", já se manifestava também a mudança, que hoje se tornou ainda mais visível, em relação à dimensão temporal sobre a qual a ênfase recai. $\mathrm{Na}$ pesquisa sobre o estudante, o jovem era considerado agente efetivo de transformação social; essa possibilidade, entretanto, era sempre posta no futuro, ainda que a partir do presente. A questão era ali colocada levando em conta que no jovem estão contidas duas situaçóes virtuais, na medida em que ele
21. Não há superposição perfeita entre a noção de presente aquela referente ao agora, que, de fato, corresponde ao presente mais imediato, aquele que ocorre exatamente "neste momento". Entretanto, nesta discussão, esses termos serão usados como sinônimos para que não ocorram demasiadas repetiçôes de palavras. 
é ao mesmo tempo jovem e estudante: sua condição juvenil

22. Como lembra Bourdieu (1998, p. 121), “a insegurança objetiva funda uma insegurança subjetiva generalizada”.

23. Novotny refere-se ao futuro como uma categoria em extinção, suprimida e substituída pelo presente estendido ou prolongado. Desse modo, ele não pode mais ser tomado como certo. O futuro realizarse-ia agora, determinado por esse presente ampliado, que passa a absorvê-lo. Problemas que antes eram remetidos a um tempo futuro penetram o presente e impõem soluçôes que poderiam esperar o amanhã, mas exigem ser tratadas hoje mesmo. Dessa forma, o futuro não mais oferece o campo livre para a projeção dos desejos, esperanças e crenças, cada vez mais obscurecido pelas questôes do momento. Criase, em conseqüência, uma dinâmica própria do presente; ele se converte em seu próprio centro (Novotny, 1992, p. 48).
[...] faculta-lhe discernir, no plano familiar, a seqüência de geraçōes que o antecederam e avaliar criticamente [...] o mundo que [as] envolvia, separando-o, com nitidez, do presente. A condição de estudante transforma-o, por sua vez, aos olhos da família e quiçá aos seus próprios, no presente vivo diante do qual não é mais possível se omitir (Foracchi, 1965, p. 100).

Sendo esse presente vivo, no entanto, "ser estudante é condição especial, que pressupõe o preparo gradativo e dosado para uma atividade social futura [...] para um modo definido de participar da sociedade de seu tempo. $E$, portanto, uma virtualidade eminentemente voltada para o futuro" (Idem, pp. 211-212; grifos meus).

De qualquer forma, o futuro possivel depende dos processos em curso na sociedade inclusiva e da posição ocupada pelo jovem e sua família. Desse modo, a perspectiva a partir da qual é vislumbrado está voltada para o momento em curso, radica-se nele e, assim, "é incerto como solução e indefinido como opção - é um futuro limitado pela perspectiva do presente" (Idem, ibidem).

Não é distinta a representação do porvir atualmente predominante, ainda que se possa dizer que a incerteza, a indefinição e os limites aludidos acima sejam ainda mais acentuados. Diante da indeterminação e da inseguranç $^{22}$ que acometem a vida individual e coletiva, nos mais diversos níveis, a perspectiva de futuro fica cada vez mais nebulosa. Em virtude disso, as pessoas vêem a percepção processual do tempo alterada, o que lhes dificulta o estabelecimento de vínculos entre o que foi e o que é, e, conseqüentemente, impede a projeção do que virá a ser.

Em relação a esse ponto, diz um autor: podem ser encontrados jovens que "olham o futuro com os pés firmemente apoiados no chão" (Calvo, 2001, pp. 77-102, apud Pais, 2003, p. 122). Todavia, muitos deles tendem a fantasiá-lo ou a vê-lo como um campo aberto de possibilidades, desse modo esperando "que o presente se revelará, que as coisas acontecerão” (Pais, 2003, p. 122). Para outros, similarmente ao que foi constatado por Foracchi (1965, p. 212), "o futuro é, virtualmente, uma experiência do tempo presente"; nesse caso, "a preocupação a respeito do futuro é compensada pelo maior valor atribuído ao presente" (Pais, 2003, pp. 124, 125), que é, desse modo, prolongado ${ }^{23}$.

Similaridade, entretanto, não significa identidade absoluta. $\mathrm{Na}$ atualidade, a percepção do futuro como virtualidade do presente não está fundada, 
como no caso mencionado acima, em certa estabilidade conquistada, num futuro que significa, ao mesmo tempo, pôr em movimento a formação profissional obtida com o curso universitário e reiterar a posição social atingida pelo núcleo familiar, ou seja, um futuro limitado, mas até certo ponto confortável.

A análise da relação entre juventude e presente merece, ainda, que se observe outro ponto. Trata-se da aparente desconexão operada por alguns entre aquilo que foi, o que é e o que, presumivelmente, será. Diferentemente do que se costumava supor, para alguns membros dos grupos mais jovens as condutas desenvolvidas e as atitudes tomadas no presente aparentam não ter conseqüências posteriores. É como se a vivência do presente sempre renovado impedisse a percepção dos vínculos existentes entre o que foi, o que está sendo e o que virá a ser. Nesse caso, o momento presente é vivido como um refúgio, fora do passado e do futuro, não existindo senão o instante, o prazer e a liberdade (cf. Pronovost, 2000, p. 37).

Hoje, para alguns, é possível viver de forma imprevidente e afirmar a certeza de muito sucesso, riqueza, bem-estar e felicidade em relação às expectativas quanto ao porvir. Pesquisas distintas, que trabalharam com diferentes grupos de jovens, exemplificam o que está sendo afirmado: uma delas discute as alteraçôes que ocorrem contemporaneamente nas formas do trabalho, e compara percepções e perspectivas de trabalhadores jovens e maduros (cf. Evelyn, 1998); outra analisa o lazer da juventude paulistana pertencente às camadas médias (cf. Pimenta, 1998). De forma contraditória, ao lado de acentuar a urgência pelo gozo do tempo presente e indicar a necessidade de consumi-lo exaustivamente como se fosse o único disponível (desse modo sugerindo descrença quanto à possibilidade de um futuro vir a suceder esse presente), expressando o que se poderia identificar com um wishful thinking, tanto os jovens trabalhadores como os jovens de camadas médias entrevistados nessas pesquisas anunciam um futuro promissor para si próprios, como se o hoje e o amanhã não tivessem conexão e entre eles não houvesse nenhum vínculo de sucessão ${ }^{24}$.

Paradoxalmente, nos dois casos, as atividades que ocupam seu tempo de forma prioritária - refiram-se elas ao trabalho remunerado, enfocado pela primeira, ou ao estudo, presente na segunda - são encaradas pelos jovens como se não contribuíssem para a construção da própria vida e para a constituição de sua identidade; antes, mesmo sendo, aparentemente, resultados de "livre escolha", parecem-lhes externas, estéreis, áridas, vazias de sentido e - esse é o elemento que se quer acentuar - indiferentes para o delineamento do que virá a ser.
24. É interessante constatar que pesquisa desenvolvida com jovens europeus expõe esse mesmo tipo de comportamento no que diz respeito ao privilégio do presente e à abstração do futuro. Cf. Pais (1998).

novembro 2005 
25. Enquetes realizadas para apreender o emprego do tempo pelos jovens canadenses de 15 a 24 anos, nos anos de 1986, 1992 e 1998, encontraram resultados que ratificam o que as pesquisas brasileiras registraram: quando esses três anos são comparados, é possível perceber a diminuição dos períodos de tempo dedicados ao sono, ao trabalho e às atividades escolares e o aumento significativo do tempo dedicado ao lazer. Entretanto, o autor do artigo citado enfatiza que a categoria etária com mais tempo livre não é composta por jovens, mas por idosos (cf. Pronovost, 2000, pp. 34-35).

26. Trata-se de grupos focais organizados como parte da investigação em andamento, Trajetórias juvenis, de Melissa de Mattos Pimenta, cujos resultados farão parte de sua tese de doutorado.
Ao lado dessa verificação, ambos os estudos também demonstram que, hoje em dia, tanto para os jovens trabalhadores como para os jovens oriundos das camadas médias não é aceito que o tempo livre disponível seja preenchido por procedimentos que eles classificam como atividades que exigem esforço (ou pareçam aborrecidas ou, ainda, provoquem cansaço). Para os jovens das camadas médias, "o tempo do estudo e o tempo de trabalho opõem-se ao tempo de lazer. Por mais que estejam estudando na área que escolheram, [...] cursar a faculdade não é referida como uma atividade prazerosa, e sim como uma obrigação, que provoca pressão, tensão e stress" (Pimenta, 1998, p. 70). Manifestam recusa absoluta a permanecer em casa nos fins de semana, principalmente à noite, para atividades de estudo ou de aperfeiçoamento. O lazer não pode ser confundido com nada que lembre dedicação e esforço; prazer e dificuldade parecem incompatíveis; desse modo, o tempo livre só pode ser bem aproveitado na balada. No caso dos jovens trabalhadores, por outro lado, é sempre rejeitado "o que se parece com o trabalho ou aquilo que é obrigação, como os compromissos de família, mas não há vontade ou disponibilidade para algo dife-

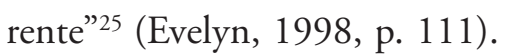

Essa perspectiva não é a única, porém. Em investigação que objetiva identificar valores juvenis e processos de transição para a vida adulta, observando jovens de diferentes faixas etárias, situações profissionais e familiares, pertencentes a distintas categorias sociais, é percebida outra representação ${ }^{26}$. Jovens moradores da periferia da cidade de São Paulo manifestaram expectativa muito pessimista quanto ao futuro, em relação ao qual não têm muitas esperanças. Para eles, mais do que incerto - na medida em que se vêem ameaçados no presente, não descortinam para si a possibilidade de uma vida melhor -, o porvir parece muito pouco promissor e, em virtude disso, projetam e desejam para seus filhos situaçōes diversas daquelas em que vivem, sem, no entanto, possuírem quaisquer bases concretas para essas cogitações (Pimenta, 2005).

Dessa forma, como é possível perceber, existem variações na relação dos jovens com o tempo: para alguns, diante da incerteza quanto ao futuro e das satisfações que o presente torna disponíveis, é essa dimensão temporal que deve receber mais atenção, que deve ser vivida de modo intenso; para outros, principalmente aqueles que se integram ao mundo do trabalho, há uma antecipação do porvir, o presente representando uma passagem em direção ao futuro, à vida adulta - identificada com a capacidade de independência -; para outros, ainda, entretanto, ocorre a constatação de que "o 
mundo do trabalho para o qual foram socializados não existe mais" (Jar$\operatorname{dim}$, 2004, p. 193).

Esses últimos sentem sua energia minada pelas dificuldades encontradas para se inserir na vida de trabalho produtivo e, em conseqüência, no mundo, de modo que se consideram e passam a sentir-se "sem futuro", ou a vê-lo incerto e indefinido (cf. Idem, p. 229). "A incerteza quanto ao futuro e às possibilidades de inserção aparece como fonte de sofrimento, como algo que suspende o início da vida adulta e a assunção de responsabilidades" (Idem, p. 237). A autora lembra que se poderia opor a essa percepção o fato de que as gerações passadas, na medida em que viviam recorrentemente em situações de desemprego, também se submetiam ao signo da incerteza. Entretanto, argumenta,

[...] o sentido [dessa] incerteza era diferente, pois não chegava a pôr em cheque as demais formas de experiência do tempo e do espaço. Hoje, a insegurança dos jovens em relação ao trabalho coloca-os numa zona liminar, na medida em que desloca os significados que ele possui, impulsiona a construção da identidade por outras vias [e] desorganiza as relações entre gerações (Idem, p. 237).

Nesse contexto, instabilidade, precariedade e incerteza tornam-se as novas condiçôes de "normalidade" e surgem como regras de vida, as quais, entretanto, não parecem amparadas por um horizonte de mobilidade. É evidente o contraste (e também a convergência) entre essas conclusões e aquelas apresentadas por Foracchi sobre essa mesma questão, mencionadas acima. Afinal, ela constata muito bem: "Não parece razoável supor que uma sociedade que ofere[ce] alternativas de vida tão insatisfatórias para os jovens seja uma sociedade integralmente aceita pelos adultos" (Foracchi, 1972, p. 13).

Ainda com relação à perspectiva de futuro, finalmente, há aqueles - por certo representados não apenas por pessoas mais jovens - para quem "o presente aparece [...] como resultado de uma piora progressiva, como um tempo limite" (Jardim, 2004, p. 263). Na opinião dessas pessoas, uma saída só poderá existir se houver a intervenção de um deus ex machina ${ }^{27}$. Podese perceber que, nesse último caso, que não é incomum e atinge um conjunto muito amplo de situaçôes e de faixas etárias, a falta de segurança revelada nas condiçôes atuais de vida, em que ressaltam o desemprego, as perspectivas incertas na velhice e os infortúnios da vida urbana - é a principal fonte "da difusa ansiedade em relação ao presente, ao dia de amanhã e ao futuro mais distante" (Bauman, 2001 [2000], p. 196).
27. Para uma reflexão sobre situações-limite abrangidas por essa consideração, ver Spagnol, 2002. 
28. "Essa idade é provavelmente aquela que suscita o maior entusiasmo, pois está aberta a todos os possíveis. Mas, ao mesmo tempo, ela deixa pairar tantas incertezas em face do futuro que cria a impressão de impotência, conseqüentemente de temor, diante das orientaçôes a serem tomadas" (Gauthier, 2000, p. 23).
Em decorrência da incerteza relativa ao futuro, outro elemento a considerar diz respeito à simbiose que a contemporaneidade estabelece entre juventude e presente, tema já introduzido acima. De um lado, trata-se da valorização social desse estágio da vida, percebido como um período privilegiado, em que os compromissos parecem ser menos prementes e a alegria de viver se manifesta de modo mais exuberante. De outro, trata-se da alteração em curso na vivência social do tempo.

De qualquer forma, o destaque que é dado ao presente não significa que seja fácil vivenciá-lo; inclusive, talvez a alternativa oposta seja mais verossímil. Se for lembrado que o prognóstico do futuro é delimitado pela vivência de um presente problemático, é possível compreender a relutância juvenil em enfrentá-lo. Marialice menciona a propósito um estilo novo de adaptação que denomina de vinculação experimental ao presente, o qual envolveria um processo de socialização específico no qual são rejeitados os objetivos culturais propostos e os recursos institucionais mobilizados para sua concretização (cf. Foracchi, 1972, p. 108). Nesse processo, como foi antes pontuado, também a condição de adulto é rejeitada por ser considerada muito restrita em possibilidades, diante dos obstáculos impostos pela estruturação da sociedade inclusiva. Dessa perspectiva, "no limite, é essa também a recusa do adulto que, como o jovem, é confrontado pela dificuldade de viver o presente" (Idem, p. 13).

Parece interessante articular a ênfase no presente com as características manifestas pelas pessoas mais jovens. A juventude é vista como o futuro da sociedade, segundo valores e critérios das geraçôes que a precederam, as quais viveram suas próprias juventudes num tempo passado (o seu presente), que foi crucial para a definição de sua identidade ${ }^{28}$. Para os jovens de agora, entretanto, é possível supor que esse passado - o "tempo" de seus pais e avós - pareça muito distante e se revista de pouco conteúdo valorativo e simbólico. Afinal, o sentimento de pertença, o enraizamento, que configura a participação num destino comum, é distintamente vivenciado por diferentes gerações que compartilham acontecimentos e situações num mesmo período de tempo. Para algumas formulaçōes, os jovens percebem a vida cada vez menos "como uma janela aberta para o futuro; [antes, ela] fascina pela ilusão de um eterno presente" (Furter, 1967 [1965], p. 15).

O comportamento juvenil da atualidade é, então, compreendido como a busca continuamente reiniciada pela vivência do presente - percebido como tempo de flexibilidade e de mobilidade, de ausência de compromisso, em que o lazer e a aventura têm um papel predominante e a possibili- 
dade da emergência de perspectivas e dimensóes novas para a existência é sempre valorizada. A avaliação dessa característica, entretanto, varia.

É necessário lembrar que viver no presente pressupóe certo tipo de orientação para o futuro. Quando isso já não mais ocorre, quando o agora se transformou na única realidade temporal existente, fica difícil manter um sentido para a vida, tanto quanto pensar e lutar por alternativas desejáveis para aquilo que está por vir. Nessas circunstâncias, vale a pena lembrar a reflexão de Bauman a respeito:

[...] os homens e mulheres do presente distinguem-se de seus pais vivendo num presente "que quer esquecer o passado e não parece mais acreditar no futuro". Mas a memória do passado e a confiança no futuro foram, até aqui, os dois pilares em que se apoiavam as pontes culturais e morais entre a transitoriedade e a durabilidade, a mortalidade humana e a imortalidade das realizaçōes humanas, e também entre assumir a responsabilidade e viver o momento (Bauman, 2001 [2000], pp. 148-149).

Da mesma forma, é interessante refletir sobre a visão de Bourdieu:

[A] capacidade de se projetar o futuro [é] condição indispensável de todas as condutas ditas racionais [...]. Paradoxalmente, [...] para conceber um projeto revolucionário, isto é, uma ambição raciocinada de transformar o presente por referência a um futuro projetado, é preciso ter um mínimo de domínio sobre o presente (1998, pp. 121-122).

O que ambos os comentários deixam patente é que a possibilidade de viver o próprio tempo de modo criativo está em íntima conexão com o apoio no tripé que compõe a experiência do tempo. Viver o presente, sim, mas sem desconsiderar que o que hoje ocorre tem seu fundamento no ontem e que a vida vivida no presente alicerça as possibilidades do amanhã. As dificuldades provocadas por um tempo em que o movimento constante e a impossibilidade de âncoras resistentes inviabilizam (ou obstam em grau máximo) a "segurança ontológica" 29 , considerada fundamento importante da identidade socioindividual (Giddens, 1991 [1990], pp. 95-97), restringem igualmente as possibilidades de identidades bem constituídas. Paralelamente, fazem emergir questionamentos a respeito dessa temporalidade em que presente, passado e futuro parecem não mais compor as dimensões constitutivas do tempo.
29. Essa expressão tem a ver com segurança, estabilidade e "confiança" de que o que estou fazendo hoje encontrará as conseqüências esperadas amanhã (Giddens, 1991 [1990], pp. 95-97). Manifesta a crença de que a continuidade entre passado, presente e futuro será mantida e de que permanecerão as condições que tornaram essa projeção possível. Demonstra a importância da previsibilidade de inserção de cada um no mundo e implica, de um lado, a sensação de "ter raízes", a percepção de "fazer parte de", e, de outro, a expectativa de que é possível continuar sendo aquilo que se crê ser, pois permanecerão constantes as condições materiais e os ambientes nos quais a vida se desenrola. 
30. Conforme certa visão, "o futuro já não é o que costumava ser" (cf. Vaz, 2003, p. 69). Se existem mudanças na qualificação e no significado de qualquer uma de suas dimensões, sem dúvida o próprio tempo sofreu mutação a ser considerada.
Entretanto, talvez seja o momento de acreditar que a história não apresenta problemas e questôes impossíveis de serem resolvidos. Se isso for feito, as dificuldades ora percebidas como rupturas ameaçadoras poderão adquirir outra conotação, emergindo como ocasiōes para descobertas que dêem sentido novo a esse processo. Se o nosso é o tempo de uma tal mudança que o próprio tempo já não se manifesta do mesmo jeito costumeiro ${ }^{30}$, é necessário aprender a conviver com ele - e nele. Se não podemos mais apelar para o passado, nem parece promissor aspirar pelo futuro, é necessário que o presente seja desvendado e a partir dele seja construída uma nova perspectiva quanto à temporalidade. Isso significa, talvez, que a mudança de ênfase sem demasiado apego ao passado e sem expectativas inconseqüentes quanto ao futuro - possibilite a descoberta de respostas mais adequadas às demandas cotidianas e permita que sejamos contemporâneos do nosso próprio tempo.

Vários outros temas abordando o objeto "juventude" poderiam ter sido trazidos para esta discussão, na medida em que, como já foi mencionado e se tentou demonstrar, a obra de Marialice Foracchi suscita interesses e indagações além daqueles incluídos no debate sobre a condição de estudante e o movimento estudantil. Entretanto, pelo tempo e espaço aqui disponíveis, teria sido impossível focalizá-los convenientemente; em virtude disso, as considerações aqui expostas parecem provisoriamente suficientes para marcar a retomada da herança intelectual que nos foi legada por "essa autora sensível, lúcida e esperançosa” (Martins, 1982).

\section{Referências Bibliográficas}

Abramo, H. W. (1994), Cenas juvenis: punks e darks no espetáculo urbano. São Paulo, Scritta/Anpocs.

AhMADI, Amir. (2001), "On the indispensability of youth for experience: time and experience in Paul Valéry and Walter Benjamin”. Time and Society (Sage), 10 (2/ 3): 191-212.

Alexander, J. (1991), "La centralidad de los clásicos”. In Giddens, A. \& Turner, J. La teoria social, hoy. México, Consejo Nacional para la Cultura y las Artes/ Alianza, pp. 22-80 (1 ed. 1987).

Bauman, Z. (2001), Modernidade líquida. Rio de Janeiro, Jorge Zahar (1 ed. 2000). 
Benjamin, W. (1985a), "Experiência e pobreza”. In Magia e técnica, arte e política: ensaios sobre literatura e história da cultura. São Paulo, Brasiliense, pp. 114-119.

. (1985b), "O narrador. Considerações sobre a obra de Nikolai Leskov". In . Magia e técnica, arte e política: ensaios sobre literatura e história da cultura. São Paulo, Brasiliense, pp. 197-221.

Bettelheim, B. (1962), "The problem of generations". Daedalus - Journal of the American Academy of Arts and Sciences.

Bourdieu, P. (1980), “La jeunesse n'est qu'un mot”. In Questions de sociologie. Paris, Éditions du Minuit, pp. 143-154.

. (1998), "A precariedade está hoje por toda a parte". In Contrafogos: táticas para enfrentar a invasão neoliberal. Rio de Janeiro, Jorge Zahar, pp. 119-127.

Castoriadis, C. (1982), A instituição imaginária da sociedade. Rio de Janeiro, Paz e Terra (1 ed. 1975).

Corrochano, M. C. (2001), Jovens olhares sobre o trabalho: um estudo dos jovens operários e operárias de São Bernardo do Campo. Dissertação de mestrado, São Paulo, Faculdade de Educação da Universidade de São Paulo.

Evelyn, Suzanna S. (1998), A produção da vida: estudo do papel e lugar do trabalho na vida contemporânea. Tese de doutorado, São Paulo, Programa de Pós-Graduação em Sociologia, Faculdade de Filosofia, Letras e Ciências Humanas da Universidade de São Paulo.

Finkielkraut, A. (1995), The defeat of the mind. New York, Columbia University Press.

ForaCchi, M. M. (1965), O estudante e a transformação da sociedade brasileira. São Paulo, Companhia Editora Nacional. . (1972), A juventude na sociedade moderna. São Paulo, Livraria Pioneira.

- (1982), A participação social dos excluídos. Parte II - A juventude: ascensão social e rebelião. São Paulo, Hucitec.

Furter, Pierre. (1967), Juventude e presente. Rio de Janeiro: Paz e Terra (1 ed. 1965).

Gauthier, Madeleine. (2000), "L'âge des jeunes: 'un fait social instable”. Lien Social et Politiques - RIAC, 43: 23-32. Montreal, Canadá.

Giddens, Anthony. (1991), As conseqüências da modernidade. São Paulo, Editora da Unesp (1 ed. 1990).

Heller, Agnes. (1981), Para cambiar la vida. Barcelona, Editorial Crítica (1 ed. 1980). Jardim, Fabiana Augusta Alves. (2004), Entre o desalento e a invenção: experiências de desemprego em São Paulo. Dissertação de mestrado, São Paulo, Programa de PósGraduação em Sociologia, Faculdade de Filosofia, Letras e Ciências Humanas da Universidade de São Paulo.

LAGRÉE, Jean-Charles. (s/d), "Lês jeunes dans le débat européen: de l'èreindustrielle à la post-modernité". Agora Débats Jeunesses, 5. 
Mannheim, K. (1952), “The problem of generations”. In Essays on the Sociology of Knowledge. London, Routledge and Kegan Paul.

Martins, J. S. (1982), “Apresentação”. In Foracchi, M. M. A participação social dos excluídos. São Paulo, Hucitec.

Novotny, H. (1992), Le temps à soi: genèse et structuration d'un sentiment du temps. Paris, Maison des Sciences de L'homme.

Oliveira, R. C. (2001), Jovens trabalhadores: representações sobre o trabalho na contemporaneidade. Dissertação de mestrado, São Paulo, Departamento de Sociologia, Faculdade de Filosofia, Letras e Ciências Humanas da Universidade de São Paulo. (2005), A constituição de si e a significação do mundo: uma análise sociológica sobre jovens trabalhadores. Tese de doutorado, São Paulo, Departamento de Sociologia, Faculdade de Filosofia, Letras e Ciências Humanas da Universidade de São Paulo (a ser defendida).

PAIs, J. M. (1999), Consciência histórica e identidade: os jovens portugueses num contexto europeu. Lisboa, Celta.

(2003), "The multiple faces of the future in the labyrinth of life". Journal of Youth Studies, 6 (2): 115-126.

Peralva, A. T. (1997), "O jovem como modelo cultural”. Revista Brasileira de Educação, 5-6: 15-24 (Número especial: "Juventude e contemporaneidade").

PimenTA, Melissa de Mattos. (1998), "Dos embalos de sábado à noite à reggae night: um panorama sociológico dos night clubs em São Paulo”. Relatório final de bolsa de Iniciação Científica, Fundação de Amparo à Pesquisa do Estado de São Paulo/Fapesp (mimeo).

. (2001), Jovens em transição: um estudo sobre a transição para a vida adulta entre estudantes universitários em São Paulo. Dissertação de mestrado, São Paulo, Programa de Pós-Graduação de Sociologia, Faculdade de Filosofia, Letras e Ciências Humanas da Universidade de São Paulo.

.(2005), Trajetórias juvenis. Pesquisa de doutorado, em andamento. São Paulo, Programa de Pós-Graduação de Sociologia, Faculdade de Filosofia, Letras e Ciências Humanas da Universidade de São Paulo.

Pronovost, Gilles. (2000). "Les jeunes et le temps". Lien Social et Politiques - RIAC, 43: 9-21. Montreal, Canadá.

SADER, Eder. (1988), Quando novos personagens entram em cena: experiências e lutas dos trabalhadores da Grande São Paulo, 1970-1980. Rio de Janeiro, Paz e Terra.

SiLva, C. A. F. (2003), Trabalho e quimeras: dilema vivido pelo jovem operário. Dissertação de mestrado, São Paulo, Departamento de Sociologia, Faculdade de Filosofia, Letras e Ciências Humanas da Universidade de São Paulo.

Singly, François. (2000), "Penser autrement la jeunesse". Lien social et politiques RIAC, 43: 33-40. Montreal, Canadá. 
Sousa, J. T. P. (1999), Reinvençôes da utopia: a militância política dos jovens nos anos 90. São Paulo, Hacker Editores.

Spagnol, A. S. (2002), Garotos perdidos: um estudo sobre os jovens delinqüentes na cidade de São Paulo. Tese de doutorado, São Paulo,. Departamento de Sociologia, Faculdade de Filosofia, Letras e Ciências Humanas da Universidade de São Paulo.

VAlLe, M. R. (1999), 1968 - O diálogo é a violência: movimento estudantil e ditadura militar no Brasil. Campinas, Editora da Unicamp.

VAz, Paulo. (2003), “Tempo e tecnologia”. In: Doctors, Marcio (org.). Tempo dos tempos. Rio de Janeiro, Jorge Zahar, pp. 69-92.

\section{Resumo}

Retomada de um legado: Marialice Foracchi e a sociologia da juventude

O artigo faz um balanço dos textos de Marialice Foracchi (1929-1972) em que são trabalhadas questôes relativas à juventude, sua situação e seu papel, ao conceito de geração e à coexistência de gerações, destacando sua relevância e enfatizando a importância que mantêm ainda hoje para o tratamento desses temas. Paralelamente, aspectos que configuram a questão contemporânea da juventude serão trazidos à discussão e relacionados à obra dessa autora.

Palavras-chave: Juventude; Geração; Transição; Tempo; Sociologia da juventude.

\section{Abstract}

A legacy reappraisal Marialice Foracchi and the sociology of youth

The article reviews writings by Marialice Foracchi (1929-1972) regarding youth, its situation and role, the concept of generation and the coexistence of generations, highlighting its relevance and emphasizing the weight these texts carry to this day in the discussion of these issues. Aspects to do with youth nowadays are brought up, analyzed and compared to the ideas put forward in Foracchi's writings.

Keywords: Youth; Generation; Transition; Time; Sociology of youth.

Texto recebido e aprovado em 23/11/2005.

Maria Helena Oliva Augusto é professora do Departamento de Sociologia da Faculdade de Filosofia, Letras e Ciências Humanas da USP. E-mail: mhoaugus@usp.br 